\title{
On the Fairness of the Higher Education in China
}

\author{
$\operatorname{Min} \mathrm{Li}$ \\ Shenyang University, Shenyang, Liaoning 110044, China \\ E-mail: sdjjqy@163.com
}

Received: April 5, 2012

Accepted: April 10, 2012 Online Published: May 21, 2012

doi:10.5539/hes.v2n2p163

URL: http://dx.doi.org/10.5539/hes.v2n2p163

\begin{abstract}
With the establishment of the socialist market economic system in China, the issue of social fairness has been paid more and more attentions. The fairness issue of higher education, which is responsible for training high-quality talents for the national economy construction, has become the focus of attention. We discuss and research on the fairness of the higher education, and strive to achieve the goal of education equity in China.
\end{abstract}

Keyword: Education resources, Entrance exam, Education fairness

\section{Introduction}

On July 29, 2010, National Medium and Long-term Educational Reformation and Development Outline (2010-2020) was formally announced, in which the policy of cleaning up and standardizing the entrance examination is emphasized in the systems of examination and enrollment reformation. Besides, in the measures of improving the graduates' qualities, it was emphasized that we should enhance the guidance services of entrepreneurship education and employment. "Meanwhile, this outline made more clear regulations in the relationship between the college entrance examination and the employment, which are regarded as the important issue of the fairness and achievement of higher education" (Zhu, Jinhua,2005). Apparentlly, our government plan a special focus on the fairness of education in the formulation of medium and long-term educational reformation and development, which is not only a solution to the highlight problems on the current higher education, but also a specific direction for us to the further investigation of higher education reformation and development to the common class.

\section{The Analysis on the Present Situation of the Education Fairness in Current Higher Education}

Fair education mainly refers to the educated have equal rights and equal opportunity to accept higher education, that is, the individuals in an equal society should be equal in the entrance opportunity, educational process, educational outcomes and other aspects. Any distinctive treatment or condition have been regarded as unequal education opportunity. the highest realm of modern education is "to make no social distinctions in teaching", that is, to break the boundaries of the identity, status, nationality, gender, age, region, regardless of the object, without restriction to every educator who has access to the equal opportunities and rights of education. This is not only a kind of value concept shown in the constitution and the law embodies, but also a basic guiding ideology of the development of our Chinese characteristic socialist education. However, there are still many unfair phenomena existing in the development of higher education, because of the dual constraints from the external conditions and internal factors, such as economic development, culture development, social development, population and so on.

\subsection{The Unfairness of Resources Distribution in Higher Education}

At present, the higher education in China carries out the system focusing on the local management, except for a few part of colleges, a majority of colleges are under the administration of the local government. Higher education investment is also directly from the local government so that the local higher education development is directly linked with the local economic development. There is a big gap of the economy development between eastern China and western China, as well as between urban and rural areas in the same region, leading to the unfairness of higher education caused by the gap of economic development between the regions. Generally speaking, the eastern developed regions can provide more funds and attract more university graduates, so that the number of colleges are much more than that in western China, where is less developed and less funds provided. In addition, some of the country's irrational system arrangement, especially the unfair allocation of higher education resources has deepened regional inequality of higher education. For example, the focus of national schools such as the "project 211","985” universities are mainly distributed in the eastern coastal developed areas in the western region; in contrast, a small amount in the western China. In Beijing, Shanghai and some other big cities, the level of education is significantly 
higher than that of other provinces; the quantity and quality is also far ahead as well. In the midwest Universities, there is a smaller proportion of Master's and Doctor's stations as well as a lower internationalization level. What's more, there is an obvious disparity between national key universities and local colleges in the aspects of financial investment, faculty, facilities, the input of students' cultivation funds and so on, which makes the proportion of the graduate students of subordinate colleges and universities develop at the synchronous speed with undergraduate education in higher educational level. The local colleges are confronted with a number of difficulties such as the lack of funds, teachers and students, along with the weak postgraduate education foundation and a lower research level, which asks for further improvement in all the aspacts.

The imbalance in distribution in higher education results in inequity of enrollment opportunities, namely students' different birthplaces largely determine the chances of receiving higher education; meanwhile, results in the inequity in the course of education, that is, the opportunity of students' receiving higher education is not equal, the opportunity of receiving the education services is not equal and so on (Zhu, Wenjun, \& Wang, Shaodong, 2005).

\subsection{The Potential Unfairness of Entrance Examination and Employment in Higher Education}

Since the college entrance examination has been resumed, a form of cultural examination has been using in higher education, with the exception of a few institutions implementing a certain amount of independent recruitment. The unified examination, the unified examination sheets and the unified standards of grading have been adopted to determine if the individuals have the opportunity to receive higher education. As a standard, the single intelligence test decides if a student can get access to the opportunity of receiving higher education, which actually denied those who does not adapt to the examination obtain the opportunity of higher education, which can be regarded as a discrimination on educational starting point.

At the same time, the current university enrollment system takes the method called the provincial quota and the marking admission, which mainly depends not on the number of candidates and their tests level, but on local resources in higher education and regional economic situation, directly leading to significant differences between different regions of schooling opportunities, to a large extent, exacerbating the existing inequality of the higher education among the different regions(Bie, Dunrong, \& Zhu, Xiaogang, 2003).

The phenomenon called "college entrance examination immigrants" is an outstanding performance showing the increasing use of admission rates and admission scores in recent years. Besides, when the colleges and universities carry out some systems, such as "unripe" system, "Miyoshi students, outstanding student cadres" bonus system and some other special or particular forms of enrollment, it is inevitable to lack strict and effective supervision management and lead to the inequality of receiving the opportunity of the higher education.

“There exists the unfair phenomenon at the end of students' higher education-- employment. Apparently, inequality can be found among different schools, different majors, different sources, different gender, when graduates are available for being employed" (Zhu, Chaohua, 2003). For example, because of the obvious national support offered to the key universities by the division of schools and the educational system, the employers in the society have been holding a "key plot", which means focusing on the key universities and preferring "brand effect", leading to the general college students in employment process suffering the unequal treatment, and even discrimination, which is the direct manifestation of unfair education.

As far as the majors is concerned, the demand of popular ones exceeds supply and has more chances to choose; on the contrary, the arts which trend to benefit long-term social profit have difficulty in employment and has less chances to choose, even without no access to the employment, resulting in taking up the occupations which are not involved in the original professions, which have less opportunities to be accepted than the popular ones. In addition, the graduates from different regions, different economic background, different segments will be influenced by various social factors, when their option.

\subsection{The Unfairness of Higher Education Caused by the Difference of Institutions}

There has been the obvious disparity of funds input between the national key universities and local colleges in financial investment, faculty, facilities, the students' cultivation and so on, which results in that there is a higher proportion of graduate students in the subordinate colleges and universities, equaling to the development of college education, when we refer to the higher learning culture levels. Yet, the local colleges are faced with the difficulties of lack of funds, teachers, students and so on, as well as the weakness of postgraduate education, and the low level of research, which asks for the further improvement. This imbalance in distribution in higher education leads to the inequity of entrance opportunity, namely, the region of students' birthplace largely determines the chances of receiving higher education; and leads to the unfairness in the course of education, that is to say, there is no equality of making use of higher education resources and obtaining the equal opportunity of education services, etc. 


\subsection{The New Form of Inequality in Higher Education}

"Education was of the function of regulate the fairness in our society, which makes the educators migrate from low level status to high level status” (Long, Chunyang, \& Wang, Qiang., 2003). For example, the poor children from the countryside can receive higher education so as to find jobs later in the cities, further into the city population, have a better day, even changing their social class. So the education plays the most important role of obtaining people's social status. But along with the increased enrollment, the number of graduates surge, leading to many of the college graduated students are unable to work, namely "graduation equal to unemployment". Now the employment of college graduates is also a concern of social problems: "a lot of rural children who run out of home savings or even debt have finished their study in university, however, in the end they cannot even find a job, but not to say to improve the social status; even the most basic reading cost cannot be compensated, so the function of higher education to improve the social status does not exist under this situation, which is called a kind of new educational inequity."

Secondly, the tendency of employment of college graduates also led to new unfair phenomena in education. Nowadays, a majority of the students coming from the western China go to the developed eastern coastal cities to receive higher education by enrolling into the colleges and universities. After graduation, they are reluctant to go home for the employment in the rural areas, and actually they would like remain in the developed areas even if they can't find a good job indeed, which is a disguised form of unfair education. The brain drain of graduates birthplace, causing the poor places' lack of human resource becoming poorer, makes manpower capital surplus situation in the relative developed areas and regions, though.

What's more, because of the cost sharing system of the higher education taken in China, the university tuition also is on the rise increasingly, which needs an undergraduate to spend 30000 yuan in at least 4 years--unaffordable for a poor rural family. Some families have to sell out their livestocks and property to support a college student, that is, supporting a college student means prolonged poverty. By contrast, under the current employment pressure of our country, a large number of rural graduates can not find a suitable job, causing that they are unable to repay the loan and enormous domestic investment in education have no compensation .

\section{The Countermeasures and Proposals of Promoting the Equity of Higher Education}

Researching on the fairness of higher education, the core issue is how to realize fairness, that is, the realization mechanism of the fairness of higher education. The history of the world higher education development shows that the higher education is the product of civilized system; and that the problems of higher education development and the settlement of fair problem must rely on the system to achieve. The current unfairness of higher education in our country is largely not caused by the higher educator and educatee own or natural causes, but mainly because of lack of the policy of higher education, and its relevant extending laws and regulations, system, mechanism imperfect and not sound. Therefore, how to implement and promote the fairness of higher education, how to effectively solve many of the present unfairness of higher education totally depend on deriving from the system and institutional aspects. This article discusses how to promote the measures of fairness of higher education from the allocation of educational resources and entrance examination.

\subsection{Establishing and Perfecting the Reasonal Allocation System and Mechanism of the Higher Education Resource}

"The government is the main body of the allocation of the higher education resources, so the government's how to allocate the resources of higher education directly decides the realization of the equity of higher education" (Xie, Weihe, 2008).

First of all, "we must continue to increase national finance of higher education investment, and increase input in education in total” (Shi, Rijie, 2008). Gradually, we should improve the proportion of the national financial educational expenditure in GNP, as well as the proportion of educational budgetary expenditure in the fiscal expenditure, which can ensure national financial educational funds reach to $4 \%$ of GDP, and the realization of "three growth", which includes the central and the local education funding is higher than regular revenue growth, average budgetary education expenditure grows gradually, as well as the teachers' salaries and the average public expenditure increases gradually. The realization of the fairness of higher education is based on the material foundation provided in total.

Secondly, we should establish a scientific, reasonable and fair allocation system of higher education resources. Education management departments should abide by equality, reciprocity and complementary principles, distribute the limited education resources reasonably, change the previous situation that the higher education resources are too focused on developed area and the key universities, have a reasonable proportion inside the higher education, which means that there should be a reasonable proportion not only between the key schools and the ordinary schools, but 
also between the undergraduates and graduates, in order to create a healthy competition environment for various institutions (including the public and the private, research universities and the non-research universities, and so on); to recombinate the higher education resources through the fiscal transfer payment or special subsidies in the form of laws; to increase the investment to the disadvantaged in the disadvantaged areas; and to eventually achieve the balanced development by the implementation of the basic spirit of how to treat and compensate the education. It's required to establish a reasonable system of fiscal transfer payment, a system of teachering resources' flow, and a system of education resource sharing, in order to achieve the balanced development in the different regions and different levels of Universities.

Again, we should promote the establishment of a multi-channel financing mechanism of higher education funding. The state should pass legislation to not only make use of national financial funds and transfer payment, but also through tax reduction and tax exemption policies to offer the preferential loans and the support from the developed areas, which aim to encourage the donation from the society, promote the development of education in remote areas and narrow the disequilibrium of regional educational resources by making use of government mechanism, social mechanism and union of marketing mechanism, together with positive use of the capital market to raise funds for education, by offering education bonds and developing the educational investment funds, as well as international cooperation channels for the introduction of capital.

\subsection{The Reform of Higher Education Admission System}

"Our current college entrance examination system with the form of equity makes everyone equal before mark, however, iwhich also leads to some unfair phenomena” (Wang, Xuemei, 2007). Thus, the reform is needed for the current college entrance examination system, which can solve the issue of educational equity from the entrance mechanism.

At first, the diversification of examination form. To the various types and diverse levels of universities, it has been unable to meet the requirements of the development of higher education at present stage by merely using the college entrance examination, which can choose different college students with only standards -scores. The content of assessment not only includes the book knowledge, but also increases comprehensive assessment to students, changing the phenomenon of existence of students who can gain high scores without study abilities under the exam-oriented education to further promote quality education effectively. The different types of institutions of higher education can take different forms for the examination, that is, undergraduate course universities can implement a unified national examination; higher vocational colleges can carry out the provincial organization of examination and enrollment; and the higher level universities can take additional tests and encourage university entrance exam conducted among several excellent universities. Even some of the subjects tests can be performed repeatedly in one year. In conclusion, "through the diversification of examination, we can give more students more opportunities to be educated, striving for greater fairness of higher education” (Gao, Peiyong).

Furthermore, the diversification and integration of the criteria for admission. Nowadays, our country university admission is mainly through the conveyor and the independent recruitment, which depend on the only criterion--the college entrance examination scores. Obviously, it's not enough to decide whether students can get the chance of receiving higher education, just according to the college entrance examination achievement. At present, a multivariate evaluation system needs establishing to add to the college entrance examination scores. What's more, high school levels tests and comprehensive quality evaluation of the middle school students, along with the students' daily performance, moral cultivation and the abilities of all aspects should be put into the evaluation system, which can be used to evaluate students' all-around abilities. Ensure that the students with special talents can enter the better colleges and universities through various channels, striving to achieve maximum fairness of higher education.

\section{References}

Bie, Dunrong, \& Zhu, Xiaogang. (2003). Research on the fairness problem emerged on the way to the popularization of higher education in China. [J] Beijing University Education Review, 3.

Liang, Dezhi. Scientific outlook on development and Constructing Harmonious Education. [J] Journal of Chang'an University: Social Science Edition, 2007, 9(1):78-82.

Long, Chunyang, \& Wang, Qiang. (2003). The Major Needs for Education Fairness and the Priorities of Education Policy. [J] Science Technology and Management, 4.

Shi, Rijie. From Elite Education to Mass Education-Research on the Fairness and Efficiency in the Development of Higher Education. [M] Higher Education Press, Beijing, 19, 2008.

Wang, Qiang. (2005). On the Problems of Education Equity in China. [J] Journal of Wenzhou Vocational and Technical College, 2. 
Wang, Xuemei. Laws and Educational Equity. [M] Chinese agricultural science and Technology Press, Beijing, 9, 2007.

Xie, Weihe. Educational Equity and Development in China. (1990-2005). [M] Beijing, Education Science Publishing House, 13, 2008.

Zhu, Chaohua. (2003). The Essence of Education Equity and Its Social Value Analysis. [J] China Higher Education Research, 1.

Zhu, Jinhua. (2005). The education fairness: The perspective of policy.[D] A doctoral paper of Jilin University.

Zhu, Wenjun \& Wang, Shaodong. (2005). Understanding the three fulcrums of education fairness during the transition. [J] Beijing University Education Review, 1. 